\title{
El mundo es ancho y ajeno, de Ciro Alegría: Traducción y traición en la novela indigenista
}

\author{
Ximena Troncoso Araos \\ Universidad Católica del Maule \\ E-mail: xitrona@yahoo.com
}

\section{RESUMEN}

La obra de Ciro Alegría exhibe, tal vez más acusadamente que la de otros escritores del indigenismo, la pugna del escritor con el lenguaje en la tentativa de mostrar el mundo indígena 'desde dentro'. Curiosamente, la crítica elogiosa de El mundo es ancho y ajeno (1941) y la cuestionadora apuntan a un mismo aspecto: el mostrar o no el mundo indígena desde dentro. $M$ ás que abogar por una u otra crítica, me interesa sugerir a partir de la propia novela el porqué de tan contrapuestas percepciones. Reconozco que existen diversos factores externos que influyen (políticos, culturales, de institucionalidad literaria, de egos profesionales, etc.), pero los juicios finalmente se despliegan con el texto y es su carácter particularmente tenso, ambiguo, irregular y transicional, lo que provoca lecturas disímiles no sólo en sujetos distintos sino en un mismo lector.

Palabras claves: N ovela indigenista, traducción y traición, memoria, perspectiva indígena.

\section{ABST RACT}

The work of Ciro Alegría exhibits, perhaps more intensely than in other writers of indigenismo, thestruggle of the writer with language in theattempt to show theindigenous world from within. Peculiarly, the criticism that praises EI mundo es ancho y ajeno (1941) as well as the criticism that questions it focus on the same aspect: whether or not the novel shows the indigenous world from the inside. M orethan to defend one critical position or another, I am interested in exploring, taking the novel itself as a starting point, why such opposing perceptions exist. While I recognize the influence of diverse external factors (political, cultural, literary institutions, professional egos, etc.), thefinal judgmentsunfold within the text and its particularly tense, ambiguous, irregular and transitional character which provokes dissimilar readings not only in different subjects but in the same reader.

Keywords: Indigenist novel, translation and treason, memory, indigenous perspective.

Recibido: 29-03-2004. Aceptado: 25-06-2005. 


\author{
H uérfano de huérfanos \\ $\mathrm{Hijo}$ del viento \\ H uairapamushca \\ D e la luna debe ser el frío de sus ojos \\ El corazón pura tristeza \\ H abía dicho la mestiza cocinera \\ José María Arguedas, Osvaldo Torres
}

\title{
AUTOR Y NARRADOR EN LA ENCRUCIJADA
}

E MIR Rodríguez M onegal se refiere a su experiencia de lectura de la obra de - Alegría como que sus textos le transmiten la sensación de éxito y fracaso: "Exito por la convicción interior, el vigor, la simpatía honda del autor hacia sus temas; fracaso porque estas novelas, y sobre todo la más famosa de ellas, representan el final de una etapa, la última palabra de un arte de novela, sólido, bidimensional, que ya estaba completamente exhausto en 1941" (1967). Sin embargo, a diferencia de la opinión de $M$ onegal, creo que la novela de Alegría no es como una obra del siglo XIX, sino un texto que plasma en su escritura la tensión de visiones culturales y estéticas y la transición hacia nuevas formas literarias que ya hacían su aparición en esos años.

La novela indigenista muestra en su desarrollo histórico un paulatino despojamiento de modos escriturales monológicos - en términos de Bajtín-, y de visiones positivistas y románticas, cediendo a la creación de un lenguaje polifónico y mestizado, producto de un sumergirse en lo indígena pero con un bagaje occidental. Este proceso transcultural (Rama, 1987) alcanza su expresión más notable con José M aría Arguedas.

La narración en la novela indigenista es reveladora de la problemática social y cultural de Perú (Cornejo Polar, 1980 y M ariátegui, 1955). Vivir en un territorio heterogéneo racial, lingüística y culturalmente, con un proceso de mestizaje irregular y conflictivo, obliga al escritor a generar estrategias para moverse entre mundos disímiles. El recurso, el artificio que entraña un proceso de 'traducción' del mundo indígena, en alguna medida traiciona al escritor, pero también le permite experimentar modos de acercamiento a lo marginal.

El mundo es ancho y ajeno se abre con el presagio y finaliza con su cumplimiento (elemento de la novela romántica que aquí experimenta variaciones: no se trata del sino romántico). Rosendo M aqui, el alcalde de la comunidad de Rumi, asocia el mal augurio consigo mismo, con su mujer y con la comunidad. El primer cumplimiento (la muerte de la esposa) ocurre al final del primer capítulo y se trata en el segundo. Luego comienza el litigio de tierras entre la comunidad y el hacendado Alvaro Amenábar, seguido por el despojo y finalmente la 
matanza. Entre estos dosúltimos hechos ocurre el encarcelamiento y muerte de Rosendo. D e esta manera, se cumplen los tres malos presentimientos, no obstante el narrador establezca una distancia crítica entre las creencias de los indígenas y su propia forma de pensar.

El narrador hace patente su escepticismo desde una mirada que se perfila como superior, aunque siempre benevolente. Así, por ejemplo, cuando Rosendo sube a comunicarse con las montañas, como es su costumbre, contrastan: 1) la perspectiva del personaje que entiende su hacer como diálogo efectivo con las montañas, las que son percibidas como oráculos; 2) la perspectiva del narrador que explica el acto como fenómeno físico (el eco), a lo que añade la "ingenuidad" de Rosendo (con lo que, implícitamente, percibe al indígena como niño en ciertos aspectos). El narrador, una vez que ha dejado bien clara su visión del hecho, se muestra comprensivo, benevolente, paternalista. Luego que ya ha esbozado una sonrisa por la conducta de Rosendo, trata de censurársela al lector (como el profesor que, reprimiendo su propia risa, castiga la de los alumnos que se ríen del compañero).

El texto, en las acciones y el discurso, tiende a plasmar la idea, en forma indirecta, de que la asimilación del indígena es positiva, pero esta idea se vuelve problemática al momento de observar críticamente el mundo no indígena. Es necesario el progreso y éste pasa por el abandono de ciertas creencias que signifiquen una limitante y que son percibidas por el narrador como supersticiones: las brujerías de $N$ asha Suro y el encantamiento de la laguna Yanañahui.

Benito C astro es un personaje continuación de Rosendo, representa un estadio más avanzado. Benito vuelve convertido en un mestizo cultural, con lo que completa su mestizaje (recordemos que es un cholo). Significativamente, Benito no tiene padre, es producto de una violación, por lo que en su viajeincorpora la parteno indígena del padre. Sabe leer y escribir, retoma el proyecto de escuela que el viejo $M$ aqui añoraba, no cree en brujerías ni encantamientos ni se viste como los indígenas. El progresismo de Rosendo y Benito en sus distintos grados, cuenta, básicamente, con la simpatía del narrador. U na vez que Castro ha expuesto sus ideas y proyecto al pueblo, el narrador, en el fragmento siguiente comienza ratificando el acierto de ellos: "D everas, después de dos años de tenaz labor, el pueblecito se levantó allá , fuertey cómodo, y la pampa estuvo llena de hermosas siembras" (708). Sin embargo, advierto cierto matiz irónico subyacente en el discurso de Benito para ser elegido al calde, por la semejanza con los discursos políticos, que lo influenciaron en su estadía fuera de la comunidad y de los cuales adoptó también las formas:

Benito terminó accionando con ambas manos:

Yo quiero a mi comunidá y he vuelto porque la quiero. 
Q uiero a la tierra, quiero a mi pueblo y sus leyes de trabajo y cooperación. Pero digo tamién que los pueblos son según sus creencias. Aura yo les pido votar según su corazón de comuneros. Podrán echarme, pero lo que he dicho no deja de ser verdá. Tarde que temprano, la verdad se impone. Esta comunidad será fuerte cuando sus miembros sean fuertes (edición 1955: 706-707)1

El discurso del narrador obedece a una doble tentativa que podría parecer única: 1) mostrar el mundo indígena desde dentro, motivado por la compasión y la admiración; 2) interpretarlo. La dificultad de acceder a ese mundo por la diferencia y distancia entre el horizonte cultural del escritor y el del indígena genera inmediatamente la segunda tentativa. Se suma a ello el que se considere constantemente al lector como no indígena. D e acuerdo con esto, el narrador se perfila como un conocedor en un doble nivel: conocelo que hacen y piensan los personajes y tiene la capacidad de comprender e interpretar. El narrador actúa como un nexo entre dos esferas, la del indígena y la del destinatario. Se ubica entreuno y otro mundo en su condición de intérprete, pues posee conocimientos de ambos; decodifica de una esfera para codificar hacia otra. Por lo tanto, su voz corresponde a la de un sujeto superior que concibe su presencia como fundamental para que el lector acceda comprensivamente al texto. Es, como todo narrador moderno, un guía en cuanto a la composición textual y en cuanto al mundo representado. Se identifica culturalmente con lo no indígena, pero sus afectos están con el pueblo andino.

La perspectiva indígena, dela queel narrador sehacecargo, seenfoca al propio mundo (creencias, tradiciones, costumbres) y al de quienes no son indígenas, principalmente al de aquellos que constituyen el poder establecido, la legalidad.

\section{INCURSION EN LA MEMORIA IN DIGENA}

En el texto se distinguen tres tipos de discurso: directo, indirecto e indirecto libre?2. M e interesa aquí principalmente el último, porque a mi juicio es a través

${ }^{1}$ Tomás Escajadillo (1983: 53) repara en un posible matiz irónico presente en el episodio de lo "futres raros". La crítica vio aquí la explicitación de las ideas de Alegría. Si bien esto es así, lo interesante es que al mismo tiempo el matiz irónico, que a mí me parece efectivo, relativiza la posición superior del intelectual frente al indígena. Estos intelectuales, dice el narrador, "después de una larga estadía en la costa, habían vuelto a 'cazar paisajes' y demás" (663).

${ }^{2}$ El discurso o estilo indirecto libre "es un discurso que sepresenta a primera vista como un estilo indirecto (lo cual significa que registra las señales de tiempo y de persona que corresponden a un discurso del autor), pero que está penetrado en su estructura semántica y sintáctica, por propiedades de la enunciación y, por consiguiente, del discurso del personaje" (Todorov, en Hozven 1979: 111). 
de este modo narrativo que la novela consigue acercarse con mayor eficacia a los personajes y por ende al mundo de los indígenas desde dentro3.

En el estilo directo se intenta imitar el habla indígena con sus peculiaridades fonéticas. Este discurso alterna con el indirecto omnisciente del narrador, conformando un modo narrativo tradicional, impresionista. La incorporación del estilo indirecto libre proporciona la posibilidad de adentrarse en la vivencia indígena, sumergiéndose en la conciencia del personaje. D entro de esta modalidad se unen la perspectiva del personaje y la del narrador, que se corresponden con dos esferas culturales, la indígena y la no indígena (invirtiendo los términos de Jorge G uzmán blanco/no blanco, 1991).

En el primer capítulo, el narrador, con un lenguaje culto ${ }^{4}$, sigue el curso del accionar de Rosendo M aqui, sigue también sus pensamientos, su sentir y sobre todo su memoria. El narrador traduce a pensamientos lo que en Rosendo, por limitación cultural según la perspectiva del narrador, sólo es sentimiento o intuición. Elabora conceptualmente su conciencia. También en esto se percibe el contraste y la distancia entre dos mundos. La perspectiva positivista del narrador emerge al considerar a Rosendo un individuo de sentimientos antes que de pensamientos. Aunque sin ánimo peyorativo, la idea de 'pensar' que maneja el narrador es occidental, racionalista:

Y R osendo M aqui acaso pensaba o más bien sentía: “ ¿Es la tierra mejor que la mujer?". N unca se había explicado nada en definitiva.

Esto es lo que sentía también Rosendo en ese momento - decimos sentía y no pensaba, por mucho que estas cosas, en último término, formaron la sustancia de sus pensamientos.

¿Q ue él no logra explicarse nada? D igamos muy alto que su manera de comprender es amar $(25,26,75)$.

No obstante, la visión y el pensamiento indígenas, fundamentalmente analógicos, panteístas y animistas, contagian en al gunos momentos el discurso del narrador como cuando describe a Rosendo M aqui. Aquí el narrador todavía no empieza a seguir la memoria de $M$ aqui:

${ }^{3}$ Tomás Escajadillo (1983: 135-147) ha analizado un monólogo interior indirecto, el del personaje Valencio, mostrando la habilidad narrativa de Alegría y la riqueza del pasaje.

${ }^{4}$ Antonio Cornejo Polar trata el punto de vista narrativo en La serpiente de oro de Alegría en la que un personaje indígena asume en determinados momentos la voz de narrador. En esa instancia cambia su habla popular por una forma culta, lo que revela el "conflicto del hablante básico sometido a una doble y contradictoria urgencia. Por una parte se quiere ofrecer una imagen interior de la vida en Calemar, pero, por otra, la novela corresponde y es producto de un espacio sociocultural ajeno, distante" (1977: 53). 
Tenía el cuerpo nudoso y cetrino como el lloque - palo contorsionado y durísimo-, porque era un poco vegetal, un poco hombre, un poco piedra (...) Tras las duras colinas de los pómulos brillaban los ojos, oscuros lagos quietos. Las cejas eran una crestería. Podría afirmarse queel Adán americano fue plasmado según su geografía; quelas fuerzas de la tierra eclosionaron en un hombre con rasgos de montaña. En sus sienes nevaba, como en las del U rpillau. El también era un venerable patriarca (27).

El lenguaje metafórico cobra una significación especial si lo entendemos relacionado con la vivencia indígena, concretamente con las correspondencias entre los seres humanos y la naturaleza, así como entre todas las cosas. Los indígenas se perciben y viven ligados simbióticamente a la naturaleza, con lo que son "un poco vegetal, un poco hombre, un poco piedra". El indígena no quiereimitar, devienetales los elementos por el modo de relacionarse con ellos. Es sumamente interesante que en medio del vegetal y del mineral se ubique al hombre y que al igual que en los otros dos casos se diga que era "un poco hombre". Aquí Alegría percibe un aspecto esencial de lo indígena y es que el hombre abandona el ser hombre como categoría superior, proyectándose hacia otras formas del ser quetienden a lo colectivo. Lo quele da mayor val or estético a esta descripción es la consonancia entre el lenguaje metafórico utilizado y la propia visión que el personaje tiene de su entorno y de sí mismo. Sin duda que se aprecia también el sustrato cristiano (me referiré a esto más adelante), el que se une a lo indígena en el hecho de concebir un Adán de la tierra americana, un Adán indígena.

La novela se inicia con la perspectiva de Rosendo, por medio de una sola palabra en estilo indirecto libre, es decir, el narrador verbaliza lo que está en la mentede Rosendo: “ $D$ esgracia!”. Esla perspectiva del personaje, pues la asociación entre la serpiente que se cruza en el camino y el mal augurio es creencia indígena. Tal perspectiva se destaca con el uso de los signos exclamativos, expresando así emoción, vivencia. Esta palabra se va a repetir cuatro veces en la tres primeras páginas, alternándola con el discurso indirecto del narrador.

0 tra modalidad en que funciona la alternancia es la que presenta la perspectiva del personaje indígena e inmediatamente le sigue la perspectiva del narrador, eminentemente interpretativa. Así, por ejemplo, cuando Rosendo contempla los cerros, el narrador los describe del modo como posiblemente se le figuran a este personaje.

${ }^{5}$ M e parece conveniente entender el término 'devenir' como lo desarrolla Gilles D eleuze, ya que es más apropiado para hablar del modo como el indígena se relaciona con su entorno. 
G ozaba viendo el nevado U rpillau, canoso y sabio, como un antiguo amauta; el arisco y violento $\mathrm{H}$ uarca, guerrero en perenne luchacon la niebla y el viento; el aristado $\mathrm{H}$ uilloc, en el cual un indio dormía eternamente de cara al cielo; el agazapado Puma, justamente dispuesto como un león americano en trance de dar el salto; el rechoncho Suni, de hábitos pacíficos y un poco a disgusto entre sus vecinos; el eglógico M amay, que prefería prodigarse en faldas coloreadas de múltiples sembríos y apenas hacía asomar una arista de piedra para atisbar las lejanías; y éste y ése, y aquél y esotro... el indio Rosendo los animaba de todas las formas eintenciones imaginables y se dejaba estar mucho tiempo mirándolos. En el fondo de sí mismo creía que los Andes conocían el emocionante secreto de la vida (24).

Las canas de Rosendo se comparan con la nieve de las montañas; se invierte la analogía anterior, ahora es la montaña la que adquiere caracteres humanos: el U rpillau es canoso y sabio, como un amauta o como Rosendo. La naturaleza se acerca al ser humano: Ios montes son ya un amauta, ya un guerrero, en otro duerme un indio.

La presencia de lo no indígena del narrador se delata por: el uso de la frase "león americano", en la que se entiende un conocimiento más amplio del mundo al especificar el rasgo americano; la palabra eglógico, que pertenece a una esfera culta y literaria; el concepto "animaba" relativo al animismo, término acuñado por la antropología; y el término "creía", a través del cual refiere a lo indígena, pero marcando su perspectiva diferente.

Si bien la mayor parte del primer capítulo podría entenderse como discurso indirecto libre o interiorizado, pues el narrador sigue el fluir de la conciencia de $\mathrm{M}$ aqui, principalmente sus recuerdos, la forma que adopta lo acerca mucho a un estilo indirecto, ya que la perspectiva del narrador es la que adquiere mayor presencia. Los momentos en que se siente la perspectiva del personaje son más escasos. Consisten mayoritariamente en frases que tienen como función recordar al lector que lo que se narra corresponde a la conciencia del personaje. Para ello se recurre a expresar desconocimiento o conocimiento parcial de cosas que obviamente el autor conoce y a formas léxicas populares, como cuando se tocan los temas de la Guerra del Pacífico y de los montoneros:

Diz que Chile ganó y se fue y nadie supo más de él.

En una oportunidad se al canzó a saber que pasaba un general Cáceres.

Los azules luchaban por un tal Iglesias y los Colorados por el tal Cáceres.

"¡Viva C áceres!”, " ¡M ueran los traidores", " ¡Viva Iglesias!”, " ¡V iva la patria!” ¿Por qué dirían así? Ellos sabían susasuntos $(45,46,49)$ (destacado mío).

Todas estas citas muestran la posición y actitud de Rosendo ante los asuntos bélicos y políticos del país, tanto internos como externos. Los indígenas se sien- 
ten ajenos ala guerra, pues su identidad está en relación con el terruño comunitario. Si abandonan este espacio físico, seguirán ligados a él espiritualmente; cada historia individual de los indígenas que sal en a probar suerte da testimonio de ello.

No obstante la perspectiva del narrador no desaparezca en el discurso indirecto libre usado en la novela, ya que se utiliza la lengua culta del narrador, tal modalidad obliga a reducir las interferencias personales. Con esto me refiero a juicios y comentarios, pues de todas formas el discurso es permeable a ciertas actitudes que corresponden al narrador, como cuando Rosendo recuerda la historia del pueblo en torno a la imagen de San Isidro. Estepasaje está matizado de un ligero humor que es asociable con la sonrisa benevolente, aunque en este caso expurgada de paternalismo, del narrador (58-61):

El pueblecito recibió el nombre de San Isidro del cerro y la accidentada topografía determinó que las casas estuvieran casi superpuestas, de modo que los habitantes tenían que subir por las callejas a gatas o haciendo equilibrios. Les cayó por eso el sobrenombre de chivos, en gracia al gusto por las maromas que adorna a tales rumiantes $(58)^{6}$.

\section{EXOD O, DIASPORA Y CRUCIFIXION}

Rosendo M aqui y la comunidad de Rumi están traspasados por elementos cristianos, como todo el pueblo indígena. Pero además de esta característica cultural ya conocida, la configuración literaria del personaje y la comunidad se ven traspasados por lo cristiano del mundo cultural del autor, lo que funciona en esta novela como un trasfondo (ni reescritura intencionada, ni alegoría) y se manifiesta de modo complementario en el discurso del narrador y en el discurso y accionar de los personajes.

Rosendo adquiere rasgos patriarcales bíblicos: es una especie de Salomón por la sabiduría para solucionar los problemas de la comunidad y obtiene por ello el respeto de sus hermanos comuneros. M aqui rememora -en el primer capítulo- tres casos en que resolvió con inteligencia y justicia. Uno de los casos evoca el muy conocido de Salomón en que ordena matar al niño por el que dos mujeres disputan la maternidad, la verdadera madre es la que renuncia a su derecho. Rosendo trataba desaber quién era el dueño de un potrillo, para lo que

\footnotetext{
${ }^{6}$ Este pasaje no deja de evocarme La feria de Juan José Arreola, por el estilo y el tema y particularmente la descripción de las andas de San Isidro en el día de la procesión. M e parece encontrar en Alegría un antecedente de Arreola.
} 
ordena traer a las yeguas: el potrillo reconoce inmediatamente a la madre. En seguida se explicita lo que ya era evidente: "El perdedor era acusado de malas artes, quien no se conformó y llevó el litigio ante el juez de la provincia. Este, después de oír, afirmó: 'Es una sentencia salomónica'” (31).

Lo que no es tan evidente es la relación con la figura de M oisés y con el pueblo judío, pero si reparamos en algunos momentos claves, la relación se torna bastante clara. La comunidad, luego del despojo, se convierteen un remanente que, al igual que los judíos en Egipto, se niega a ser esclavizado y por lo tanto debe huir. Esta fuga es un acto de resistencia. La comunidad experimenta el éxodo. 0 tros se dispersan por las distintas regiones, se produce la diáspora.

Rosendo es quien propone la huida a la puna, a la laguna Yanañahui, la que viene a ser una especie detierra prometida, en el sentido de concebirla como un lugar donde podrán trabajar la tierra dentro de su propio orden, libres del yugo del gamonal. Pero esa tierra prometida no es tal, porque también se les niega. En el episodio de la partida se mezclan los elementos de tres fugas bíblicas: la de Egipto, la de Sodoma y Gomorra y la de $\mathrm{N}$ azaret. Un asno transporta la figura del santo, como en el imaginario cristiano el asno transporta a la virgen y Jesús. Los comuneros cargan con un objeto sagrado como los judíos cargaban el arca; los comuneros vuelven la cabeza, al igual que la mujer de $L$ ot, para contemplar lo que dejan atrás? Rosendo, al igual que M oisés, sube a los montes a comunicarse con el taita Rumi, a "preguntar al mismo cerro por el destino".

El remanente que busca un lugar para vivir como pueblo se transforma en un Cristo crucificado, al igual que los indígenas que se dispersan por el mundo ancho y ajeno: "El indio es un Cristo clavao en una cruz de abuso. ¡Ah, cruz maldita! ¡Ah, cruz que no se cansa de estirar los brazos!" (710). N o obstante se utilice un marco bíblico que podría resultar ajeno a la configuración indígena, éste funciona hábilmente substanciado y la favorece en cuanto asume algunos de sus aspectos liberadores, aquellos que tienen que ver con lasfugas.

\section{LA FUGA DE ROSENDO MAQUI}

En el pasaje en que Rosendo M aqui está próximo a la muerte, después de la gol piza de que fue víctima a manos de los gendarmes de la cárcel, accedemos al pensamiento, sentimientos y emociones del alcalde de Rumi en su estado de semiconciencia:

${ }^{7}$ El Fiero Vásquez también hace este gesto, cuando se despide de su mujer y su hijo. En su caso se relaciona también con $M$ artín Fierro, por algunas semejanzas en sus vidas. 
Se establece aquí una relación con el comienzo de la novela: nuevamente se activa la memoria de Rosendo en relación con la comunidad, esta vez como una retahíla de imágenes en que evoca los últimos momentos vividos con su gente en Yanañahui. El narrador, con gran sensibilidad, acompañaal personaje en sus últimos instantes de vida. Ya no se trata de la nostal gia que sentía Rosendo durante el tiempo que permaneció en la cárcel, sino que ahora por su estado semiconsciente, potencia una fuga imaginativa o espiritual (contraparte de la fuga física del Fiero Vásquez), a través de la que se retrotrae a un mundo ya perdido, como si vislumbrara un paraíso distinto al del imaginario cristiano, un paraíso hecho a la medida de sus deseos y, por lo mismo, más cercano a la experiencia cotidiana. El espíritu de Rosendo M aqui escapa de la cárcel y se traslada al espacio de la comunidad, integrando los tiempos y espacios de la vida en la sierra y la puna. A Rosendo le parece estar corporalmente en ese lugar. Lo que le otorga mayor logro estético a este pasaje es que el narrador no interfiere explicándonos esto, es decir, no nos dice que a Rosendo le parecía estar ahí, sino quela descripción de la vida en la comunidad irrumpeen el discurso y en medio de esta descripción aparecela figura de Rosendo formando parte del pai saje y al mismo tiempo gestándolo por ser su mirada espiritual la que sigue el narrador. Primero se hace referencia directa a la "tierra puneña", "El Alto", para luego agregar a la descripción de este lugar los cultivos de maíz y trigo de la sierra e incorporar al espacio imaginado a personajes que ya no forman parte de la comunidad, porquehan muerto (Pascuala, el viejo Chauqui, Anselmo, también el buey $\mathrm{M}$ osco) 0 porque se han ido a otras regiones a consecuencia del despoja miento de la tierra (Benito y D emetrio Sumallacta). Los personajes y el espacio imaginados configuran a la comunidad como el lugar ideal para vivir. Todos estos personajes aparecen mencionados en el primer capítulo y tienen una gran significación para Rosendo. Cada uno representa un aspecto vital de la comunidad, por lo que Rosendo establece un vínculo afectivo con ellos. Lo individual se proyecta a lo colectivo y lo colectivo produce brotes individuales.

A continuación me detendré en estos personajes que evoca Rosendo por los sentidos que potencian en diálogo con el fragmento.

Sobre Pascuala, mujer de M aqui: Rosendo sufrela pérdida de su compañera, pero es un dolor tranquilo que se acepta estoicamente por el hecho de que Pascuala, al igual que cada ser humano, forma parte del ciclo vital de la tierra: "O bservaba que todo lo viviente nacía, crecía y moría para volver a la tierra" (94). El destino de uno es el detodos. Además, el carácter irónico de la muerte en tanto quiebre de las armonías se reduce al ser envuel to por la visión analógica (Paz, 1974). El indígena, hijo de la Pacha M ama, retorna al vientreancestral. La mujer y la tierra se asimilan. De esta manera, Pascuala establece un vínculo 
afectivo con Rosendo a nivel particular, pero se amplía a un nivel colectivo de dimensión social y mítica.

El viejo Chauqui ya es sólo recuerdo cuando empieza la novela; representa para Rosendo la memoria de la comunidad, así como él mismo se considera portador y transmisor de esa memoria. Chauqui atesoraba fascinantes historias de los antepasados, las cual es habían sido transmitidas de una generación a otra: "C hauqui era ya tierra y apenas recuerdo, pero sus dichos vivían en el tiempo", piensa Rosendo a través del narrador (36). Además de creencias y tradiciones, Chauqui transmite los hechos en que los indígenas se enfrentan con el poder de los blancos y comienzan las mayores desgracias, pérdida de tierras, desintegración de las comunidades, explotación y muerte. N uevamente lo individual se enlaza con lo colectivo. Chauqui y $\mathrm{M}$ aqui son en sus memorias individuales portadores de un acervo comunitario que tienen el deber y privilegio de traspasar.

En un momento del primer capítulo el narrador sientela necesidad deponer sobre aviso al lector, que Rosendo mezcla lo individual y lo colectivo. Su interferencia en estecaso, como en otrosa los que me he referido, reduceel dialogismo del discurso, pues en lugar de acercar al lector a la vivencia indígena, subraya la diferencia, la distancia, aunque el propósito sea bienintencionado. El narrador en ese momento percibe una vivencia indígena, pero no se deja llevar en su flujo, a diferencia del pasaje que ahora comento.

0 tros personajes evocados por Rosendo son D emetrio Sumallacta y Anselmo, quienes cultivan la música, "el arte preferido del hombre andino" (388), la flauta y el arpa respectivamente. En las historias de estos dos personajes el narrador evita las frases sapientes, explicativas, parece dejarse envolver en el flujo musical que potencia la música. A través de ella, los comuneros cantan y lloran, viven y mueren. La música es expresión individual y colectiva. La vida comunitaria en íntima relación con su espacio natural despierta afectos y emociones en el músico. Las intensidades colectivas encuentran un resonador en el alma y en el instrumento del músico, a través de los cuales surgen renovadas. La música suscita nuevos afectos o bien los estimula y los hace visibles. A través de la música y el canto se cumple un proceso de feed-back: la vida comunitaria converge en la expresión artística y luego la música, con su propio lenguaje, genera nuevas sugestiones.

El buey M osco, al igual queel viejo Chauqui, es sólo recuerdo para Rosendo al comenzar la novela. El viejo M aqui domestica a M osco en el sentido de crear lazos(ś́... como el Principito). El buey despierta un cariño especial en el al cal de, establecen una relación de amistad, la que puede entenderse a partir del modo como los indígenas se relacionan con el mundo natural. El buey comparte el trabajo con el hombre, es un "compañero": ambos son hijos de la tierra y viven 
de ella por la unión de sus fuerzas; por eso es que Rosendo "Io quería y a la vez lo respetaba, considerándolo en sus recuerdos como a un buen miembro de la comunidad" (68). El animal asume ciertos comportamientos humanos: "la justeza del entendimiento y la paz del corazón", "El al calde pensaba que los animales son como los hombres y era mentira lo de su falta de entendimiento" (72), se aproxima a lo humano, así como el humano se acerca al animal. Rosendo compara a M osco con otros toros como quien compara dos personalidades diferentes. Si bien los indígenas ya no creen ser descendientes de los cóndores (se rompela relación genética), mantienen un grado de simbiosis con el entorno, por lo que el indígena se acerca a lo animal, vegetal y mineral. Rosendo rescata entonces al buey M osco porque creó con él una relación particular, pero al mismo tiempo esa relación lo pone en contacto con la tierra y todo lo natural, visión que a su vez lo une a sus hermanos indígenas.

Retomo el pasaje de Rosendo. El narrador se compromete con la perspectiva de M aqui, lo que se percibe cuando dice: "tal vez el cuerpo de Rosendo es también como un suelo profanado". En los enunciados anteriores se compara el suelo de la comunidad con el suelo de la cárcel yuxtaponiendo las imágenes: "En las fal das del cerro los surcos son largos y anchos y huelen a bien, porque huelen a tierra. La celda no huele a tierra, huele a barro podrido, a sudor, a orines, a desgracia". C abe pensar aquí en la idea de profanación, ya quela tierra es entidad sagrada, dadora de vida, en donde sus habitantes trabajan con al egría porque lo hacen en libertad. La cárcel es la privación (injusta) de la libertad natural y como consecuencia, negación de la natural eza y la compañía humana. No obstante este enunciado tiende más hacia la voz del narrador, la expresión dubitativa "tal vez" reduceel tono mayor, el carácter interpretativo explicativo y el enunciado se suma a las otras imágenes analógicas. Es como si el narrador, en un compromiso afectivo, dedujera su propia anal ogía a partir de las percepciones y sensaciones de Rosendo.

U na imagen analógica es: "La laguna Yanañahui espejearía a un lado de la Ilanura, ojo hermoso, ojo mágico de la tierra, mirando los pastos, las rocas, los hombres, los animales, los cielos". No se trata aquí sólo de una metáfora en el discurso del narrador para designar poéticamente un objeto, sino que corresponde además a un modo de ver y relacionarse en el mundo indígena. Analogía y animismo: la laguna como un "ojo mágico de la tierra". H ay que tener también en cuenta, eso sí, que el concepto de 'magia' (no el fenómeno que designa) es parte de la perspectiva occidental del narrador. La tierra contiene un espíritu atento, por medio de su ojo acuático, al conjunto natural en el que el indígena es uno de sus el ementos. El monte R umi contiene un espíritu que se comunica, en lasformas de las nubes pueden verse ovejas que avanzan por el cielo, el maizal 
luce barba, las espigas del trigo son haces de sol, las listas del poncho son semejantes a los surcos de la quinua.

Rosendo se acerca a lo vegetal: se le ha secado como a los troncos viejos el corazón, es como tronco yerto que no puede llorar. Por otra parte, esta imagen funciona a la vez como una metáfora de la situación de los indígenas que se proyecta en una cadena metonímica. Rosendo es un tronco que en tanto resista podría retoñar; así también las comunidades, su resistencia es afirmación de una inquebrantable voluntad de vida. La comunidad de Rumi nace cuando ya muchas han desaparecido y muere resistiendo. Rosendo, Rumi, los pueblosandinos, los pueblos originarios de América, los pueblos originarios del mundo reducidos en su territorio ancestral.

Es interesante reparar en que el pasaje comienza y termina con la referencia al canto de las aves. Primero Rosendo constata un poco sorprendido, en su estado de semiaturdimiento, que cantan los gorriones. Se dice que "Ilevaba mucho tiempo sin escuchar el canto de los pájaros y encontró en la pequeña voz una cariñosa dulzura". Rosendo no escucha el canto de los pájaros durante su permanencia en la cárcel, porque estelugar lo incomunica, privándolo del contacto con la naturaleza, tan importante para él. ¿Por qué entonces en ese momento escucha a los pájaros? Porque ha evocado a $D$ emetrio y a Anselmo, los músicos del pueblo, el flautista y el arpista, quienes se ponen en contacto con la naturaleza al punto de adoptar parte de su esencia: ambos son 'un poco' pájaros. El narrador dice queel indio ha dado al instrumento extranjero "toda la condición de un pájaro cautivo y así se la ha apropiado" (387). Tal condición resalta en Anselmo por las limitaciones que sufrea causa de su invalidez. Llega a parecerse a su instrumento, es un contenedor virtual de música al que llevan a todas las fiestas y su muerte lo asemeja por última vez al instrumento con el que parecía habersefundido: "Q uiso abrazarse a la vida y se abrazó al arpa”, "algo se le rompió en el pecho con la violencia con que, a veces, estallan las cuerdas del arpa" (390). El viejo M aqui, al igual que Anselmo viene a ser un pájaro cautivo y el canto de las aves que si entegatilla la fuga espiritual como último acto en el que resiste. Lo musical le otorga ciertos puntos de consistencia; es un modo de sobrevivirse y, en un espacio ajeno, también un modo de rebelión. Así, cuando un indígena en la guerra entonaba cantos de sus lares se decía que era desertor seguro. Al final del pasaje, Rosendo evoca a $D$ emetrio y a Ansel mo como si los estuviera presenciando, pero en primer lugar menciona sus instrumentos, con lo que las figuras de los personajes adquieren mayor relevancia por la música que entregan. D emetrio es un poco flauta, un poco pájaro, y luego no sólo un pájaro sino muchos, de la misma manera que Ansel mo, en cuya arpa canta "una bandada de pájaros". El sujeto se despersonaliza, se multiplica. Cuando D emetrio toca su 
flauta solo en el monte, acompañado románticamente por la luna, está "acompañado de todo en la inmensa noche" (149). Ese todo es la naturaleza, pero también los habitantes de la comunidad: "en el caserío los que estaban despiertos mantuvieron su vigilia y los que dormían tal vez se pusieron a soñar" (148). Rosendo también se fuga hacia la región de los sueños, se disuelve en su propia visión, se fuga desde un lugar de desgracia hacia otro en donde pueda crear su espacio delibertad. Finalmente, R osendo desaparece como sujeto gramatical, al igual que Anselmo y D emetrio. $\mathrm{N}$ o hay aquí sujeto gramatical que designe persona; en su lugar encontramos la flauta, la acequia, la quebrada, la bandada de pájaros. Lo musical se conecta con lo vegetal, lo animal y lo mineral acercando así todas las materias, entre las queel cuerpo de Rosendo se ha de diluir y formará parte del ciclo de la tierra.

¿Logra fugarse Rosendo dela perspectiva del narrador? C omo discurso indirecto libre que no abandona la lengua culta, no lo hace. Pero favorecido por la interiorización que emprende el narrador, consigue arrastrarlo en buena medida, comprometiendo al autor, en su escritura (más allá del mero referente) y en su ser total, con ese mundo que también nos resulta ajeno.

Siempre hay un punto en el que Ciro Alegría se repliega en territorio conocido y seguro, quizá por temor de dejarse envolver en un flujo en gran medida desconocido. No obstante, si el autor traiciona en algún grado su intención de adentrarse en el mundo indígena, también traiciona en otro grado su postura racionalista, ordenadora. Se asoma a la vivencia del indígena, a sus modos de relación, mostrándolos en un escenario principalmente dramático. Con esta comparación teatral apunto al distanciamiento entre la perspectiva del autor y el objeto de su escritura. Ya sabemos con Cornejo Polar y M ariátegui que hay una diferencia infranqueable entre uno y otro, ya que el indigenista no es indígena; pero, por otra parte, la escritura puede generar estrategias que lo acerquen en mayor o menor grado a ese mundo. La novela de Alegría exhibe movimientos de acercamiento y distanciamiento, de fugas y repliegues.

\section{REFERENCIAS}

Alegría, Ciro. 1961. El mundo es ancho y ajeno. Buenos Aires: Losada. Arreola, Juan José.1963. La feria. M éxico: Joaquín M ortiz.

Bajtín, M ijail. 1986. Estética de la creación verbal. M éxico: Siglo XXI.

Cornejo Polar, Antonio. 1977. La novela peruana: siete estudi os. Lima: H orizonte, pp. 49-64.

Central deVenezuela. 
.1994. Escribir en el aire. Ensayo sobrela heterogeneidad socio-cultural en las literaturasandinas. Lima: H orizonte.

D eleuze, Gilles y Félix G uattari. 1997. M il mesetas, capitalismo y esquizofrenia, Valencia: Pre-textos.

Escajadillo, Tomás. 1983. Alegría y El mundo es ancho y ajeno. Lima: Instituto de Investigaciones $\mathrm{H}$ umanistas, U niversidad $\mathrm{N}$ acional $\mathrm{M}$ ayor de San $\mathrm{M}$ arcos.

Guzmán, Jorge. 1991. Introducción. Contra el secreto profesional. Lectura mestiza de César Vallejo. Santiago: U niversitaria.

H ernández, José. 1985. M artín Fierro. Santiago: Ercilla.

H ozven, Roberto. 1979. El estructuralismo literario francés Santiago: U niversidad de Chile, Facultad de C iencias Físicas y M atemáticas.

M ariátegui, José C arlos. 1955. Siete ensayos de interpretación de la realidad peruana. Santiago: Universitaria.

Paz, $O$ tavio. Loshijos del limo. 1990. Barcelona: Seix Barral. Primera edición de 1974.

Rama, Angel. 1987. Transculturación narrativa en América Latina. M éxico: Siglo XXI. Rodríguez M onegal, Emir. 1967. "H ipótesis sobre Alegría”. M undo N uevo N o 11, mayo, pp. 48-51. En: http://rll.cas.buffalo.edu/rodriguez-monegal/bibliografia/ prensa/artpren/mundo/mundo_11.htm 